\title{
Study of Depletion and Contamination Profile of Dioxins in Duck Intensive Production
}

\section{Miguel Cardo, Fernando Bernardo}

Faculty of Veterinary Medicine (FMV), University of Lisbon, Lisbon, Portugal

Email: m.o.cardo@mail.telepac.pt

How to cite this paper: Cardo, M. and Bernardo, F. (2016) Study of Depletion and Contamination Profile of Dioxins in Duck Intensive Production. Journal of Environmental Protection, 7, 2056-2066.

http://dx.doi.org/10.4236/jep.2016.713160

Received: October 20, 2016

Accepted: December 17, 2016

Published: December 20, 2016

Copyright (c) 2016 by authors and Scientific Research Publishing Inc. This work is licensed under the Creative Commons Attribution International License (CC BY 4.0).

http://creativecommons.org/licenses/by/4.0/

\begin{abstract}
During 2016, following the implementation of a dioxin contamination monitoring in poultry meat (ducks) in a slaughterhouse, a positive sample was found. The investigation identified the wood shavings used as bedding material in the duck farm as the possible source of contamination of these animals. In this episode, contamination profiles of higher and lower concentrations, seem to be very similar, being OCDD, OCDF and $1,2,3,4,6,7,8-\mathrm{HpCDD}$ responsible for $74.4 \%$ of the total contamination of those animals. The study revealed a reduction of poultry contamination after the removal of the source of contamination, with an average daily depletion percentage level ranging between $1.43 \%$ and $4.35 \%$.
\end{abstract}

\section{Keywords}

Dioxin, Depletion, Ducks, Fingerprint Analysis, Contamination Profile

\section{Introduction}

Safety of the food chain is periodically challenged due to the occurrence of PCDD, PCDF and PCBs contamination in food. During the monitoring of dioxin in 2016, in a duck slaughterhouse, higher levels than legally allowed in poultry meat for human consumption were found. The identified source of contamination of the ducks was the wood shavings used as bedding material in the poultry farm, which presented considerable high levels of PCDD/F, indicating that these materials were the likely source of contamination of the animals.

Relevant dioxin depletion studies in cow milk have been conducted notably by McLachlan and Richter, 1998 [1], Fries et al., 1999 [2], Malisch, 2000 [3] and other in pigs and broilers by Hoogenboom, 2004 [4], Pirard and Pauw, 2005 [5], but evidence on the depletion rates of dioxins in poultry is yet to be well established. Furthermore, 
studies on the transformation "in vivo" of the contamination profile during the life period in poultry, highlight the need to deepen the study in this field.

This paper addresses the study of the average depletion rates of PCDD/PCDF in ducks and of the contamination profile of dioxins. The results may provide a strong contribution for risk management in food safety incidents due to dioxin contamination in the poultry food production chain.

\section{Materials and Methods}

\section{a) Sampling}

In the implicated farm, representative samples of muscle and fat from the ducks were performed with composite samples of muscle and fat of ten ducks for each pen with 3450 ducks. The first and the second samples were collected in each pen with a difference of approximately one month to access the progress of both, the contamination level and the contamination profile.

Sampling has been conducted according to following sequence:

- Two samples of muscle and fat of ducks in the slaughterhouse;

- Ten samples from the ducks breed in the 10 existing pens in the farm $(n=10)$;

- Two samples of wood shavings $(n=2)$ tested for detection and quantification of PCDD/PCDF;

- Seven samples of muscle and fat in the six positive pens, one in each pen and two samples in pen number $9(\mathrm{n}=7)$.

The bedding material (wood shavings) of the positive pens were changed to rice husk nearly 15 days before each first sample collection, except for pens 1 and 8 , in which the change was made a week later in pen 1 and on the same day, in the case of the pen 8 .

The sample storage and transport were made according to Good Laboratory Practices to ensure sample stability and integrity, avoiding any change that could affect the reliability of the analytical procedure. Each sample was individually identified and packed immediately after collection. Litter samples were preserved in dry and dark conditions in a cool place, while muscle samples were frozen.

\section{b) Analytical Method}

The analytical method used for detection and quantification of dioxin was the USA EPA method 1613 revision B [6]. This method was developed by the Environmental Protection Agency, Science and Technology of the United States for the determination of 2,3,7,8-CDDs/CDFS replaced through octa-chlorination, dibenzo-p-dioxins and dibenzofurans in aqueous matrices, solid or tissue by isotope dilution, followed by capillary column of high resolution gas chromatography (HRGC)- high resolution mass spectrometry (HRMS).

\section{c) Statistical Analysis}

Analysis of data was carried out in accordance with the methodology of the USA EPA, for analysis of contaminants [7]. The methodology is summarized in four basic steps.

Step One: Standardization 
The concentration of congeners observed for each sample is standardized. The constituents of each sample are converted to a decimal percentage of the sum of congeners.

Step Two: Construction of the bar plot of the standard concentrations

Graphic representation of the standard concentration of the different congeners for each sample. The $\mathrm{Y}$-axis of the bar plot represents the relative amount of each congener in the sample (standard concentration) and in the X-axis it is represented the identification of the 17 different congeners. This chart will give an indication of the congeners that are present in greater concentration and if that pattern is maintained for the different samples.

Step Three: Statistical assessment of pattern reproducibility

This step concerns the used of the square of the Pearson correlation coefficient $\left(\mathrm{r}^{2}\right)$ as a measure to assess whether the profile of the concentration of congeners in the samples (compared visually on the bar plot) is statistically similar. The Pearson correlation coefficient ( $r$ ) measures the degree and direction of the correlation, positive and negative, between two variables of metric scale [8]. Thus, a table is generated with the values of $\mathrm{r}^{2}$, in which each sample is compared with all others. If all values of the square of the Pearson correlation coefficient are near 1, it can be stated that the pattern of the samples, compared in pairs, is very similar. In order to assess the similarity of the concentration of congeners profile in various samples, it was used the global average comparison which is defined as the average values of $r^{2}$ found. It is considered that the profiles are similar if the average of $\mathrm{r}^{2}$ is close to 1 and the standard deviation (SD) is next to zero.

Step Four: Evaluation of the source of contamination

Once established the congener's profile of the dioxins contaminations in each group of samples, the same methodology of the previous steps was applied to investigate a possible association between those groups.

\section{Results}

The results revealed levels with an average of $18 \mathrm{pg}$ PCDD/F-WHO-TEQ/g fat in the first samples and an average of $8 \mathrm{pg}$ PCDD/F-WHO-TEQ/g fat in the second samples (Table 1).

Table 1. Comparison of the level of contamination in samples collected over time.

\begin{tabular}{|c|c|c|c|c|c|c|c|c|}
\hline Pen & $\begin{array}{l}\text { Number } \\
\text { of ducks }\end{array}$ & $\begin{array}{c}\text { First sample } \\
\text { pg PCDD/F-TEQ-OMS/g }\end{array}$ & $\begin{array}{l}\text { Ducks age. } \\
\text { First sample }\end{array}$ & $\begin{array}{c}\text { Second sample } \\
\text { pg PCDD/F-TEQ-OMS/g }\end{array}$ & $\begin{array}{l}\text { Ducks age. } \\
\text { Second } \\
\text { sample }\end{array}$ & $\begin{array}{l}\text { Depletion } \\
\text { in days }\end{array}$ & $\begin{array}{c}\text { Average } \\
\text { depletion/day pg } \\
\text { PCDD/F-TEQ-OMS/g }\end{array}$ & $\begin{array}{c}\text { Average } \\
\text { depletion/day } \\
(\%)\end{array}$ \\
\hline 1 & 3450 & 17.1 & 40 & 18.7 & 75 & 35 & -0.05 & -2.86 \\
\hline 2 & 3450 & 9.05 & 70 & 0.76 & 95 & 25 & 0.33 & 4.00 \\
\hline 3 & 3450 & 3.23 & 42 & 0.92 & 67 & 25 & 0.09 & 4.00 \\
\hline 8 & 3450 & 47.1 & 47 & 31.7 & 81 & 34 & 0.45 & 2.94 \\
\hline 9 & 3450 & 15.4 & 40 & 9.45 & 63 & 23 & 0.26 & 4.35 \\
\hline 9 & 3450 & 9.45 & 63 & 1.29 & 110 & 47 & 0.17 & 2.13 \\
\hline 9 & 3450 & 15.4 & 40 & 1.29 & 110 & 70 & 0.20 & 1.43 \\
\hline 10 & 3450 & 24.1 & 117 & 1.30 & 159 & 42 & 0.54 & 2.38 \\
\hline
\end{tabular}


The evolution of the contamination profile of the ducks in the six pens, after the removal of the source of contamination is shown in Figures 1-6.

The Square Pearson Correlation Coefficient within each group ranged from 0.70 to 0.99 .

The profile of the samples collected in the bedding material (wood shavings) in the affected farm is presented in Figure 7. The level of contamination of the wood shavings was 239 and $39.7 \mathrm{pg}$ PCDD/F-TEQ-WHO/g and the Square of the Pearson Coefficient was $\mathrm{R}^{2}=0.99$.

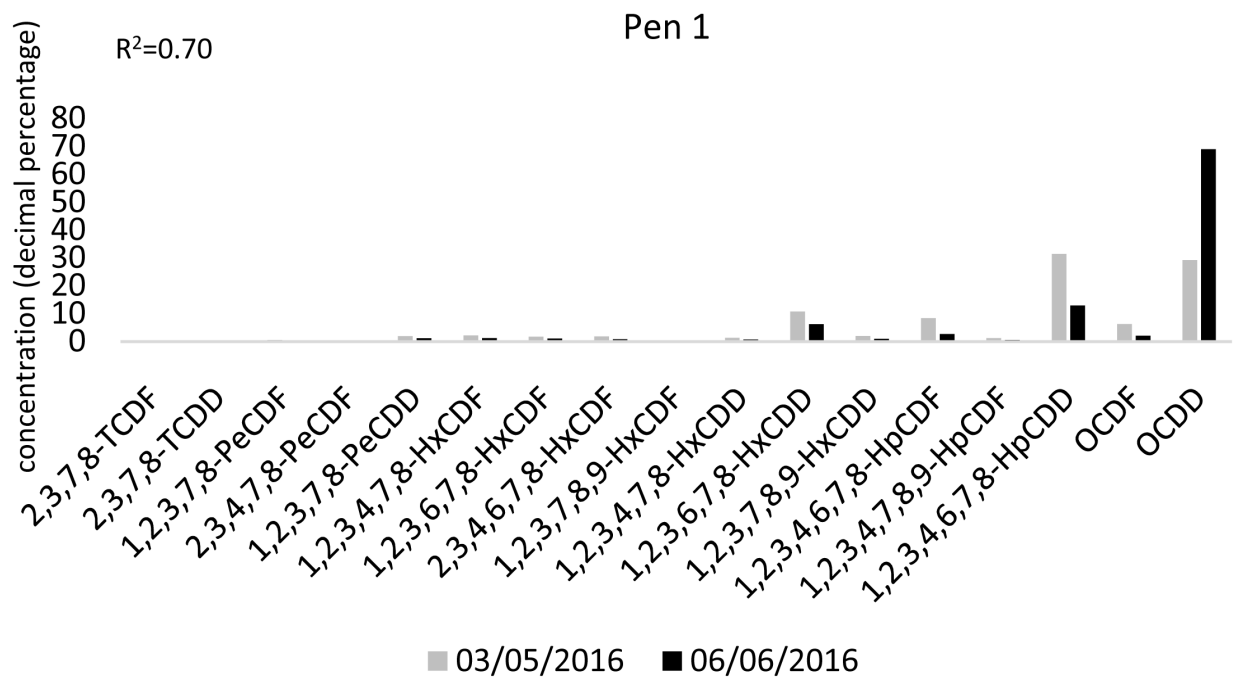

Figure 1. Assessment of contamination profile in Pen 1.

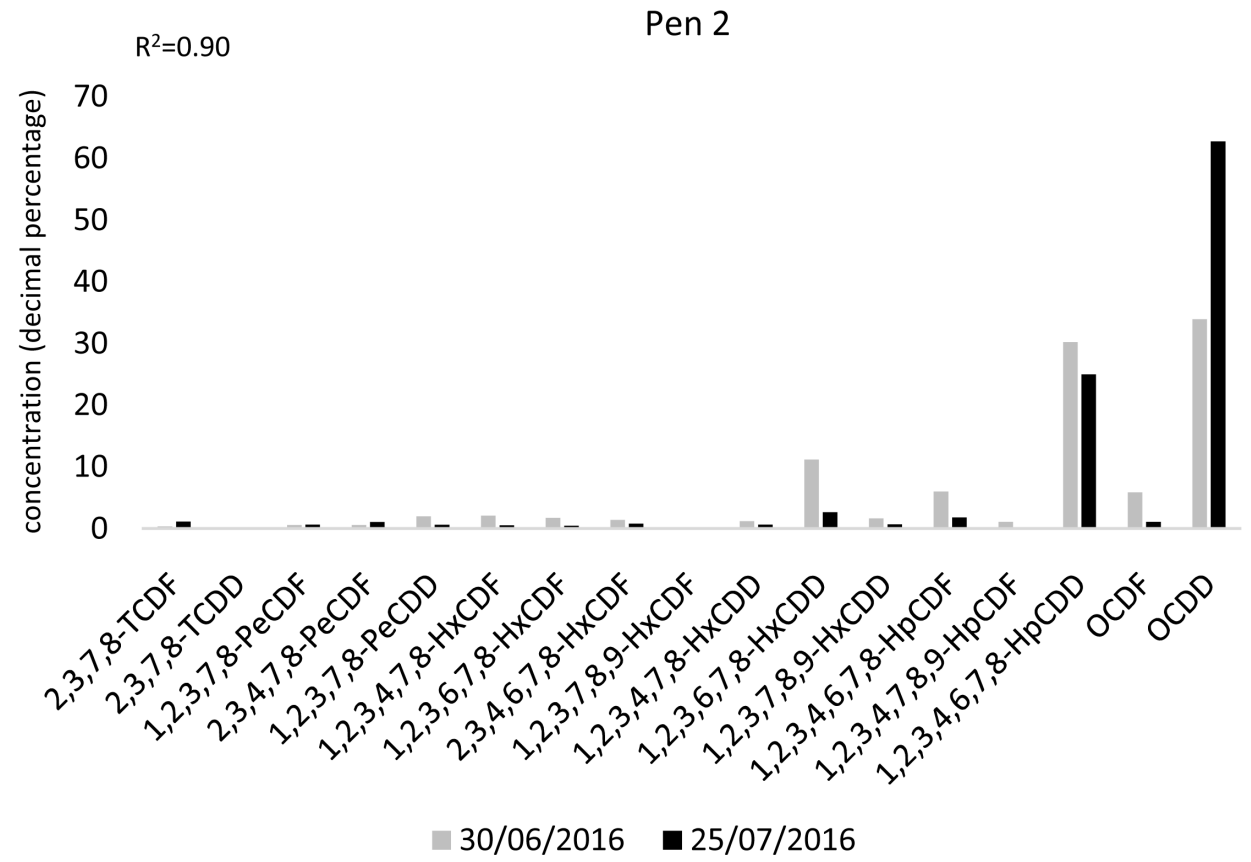

Figure 2. Assessment of contamination profile in Pen 2. 


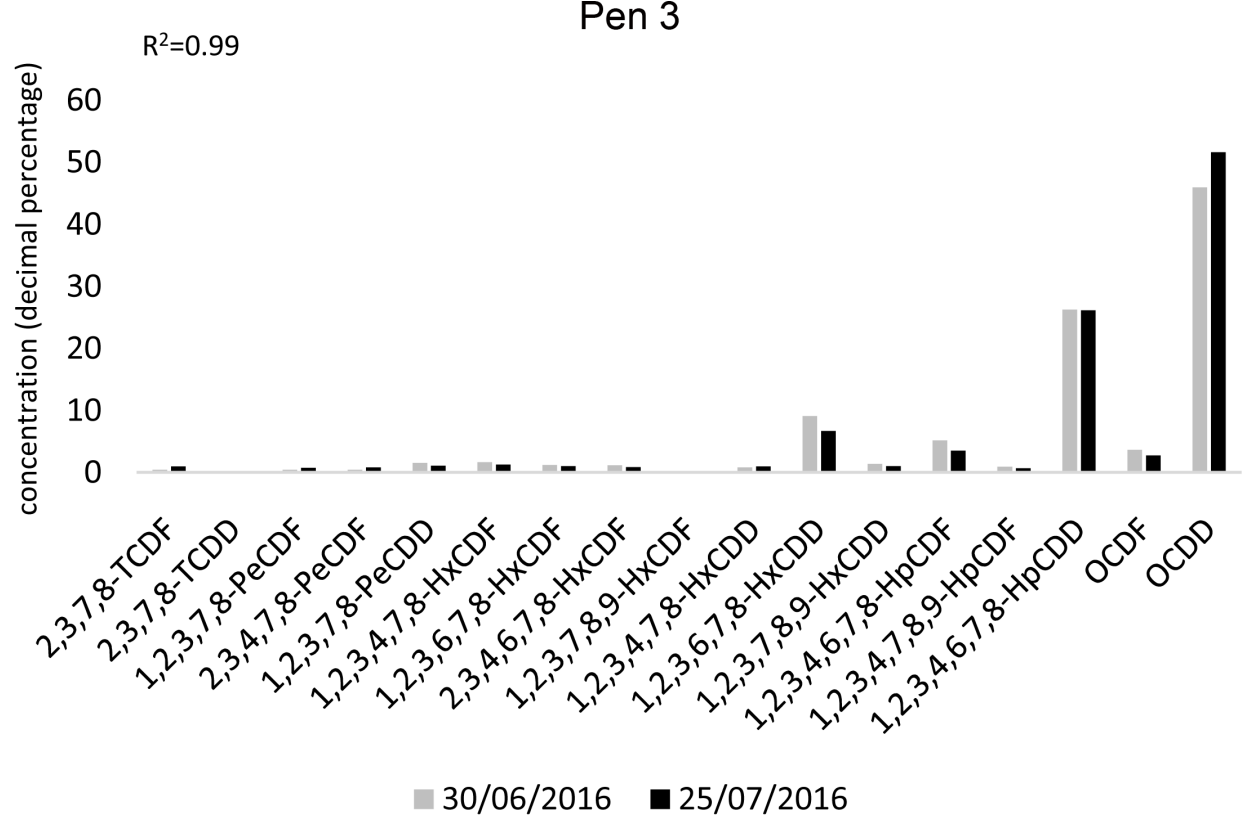

Figure 3. Assessment of contamination profile in Pen 3.

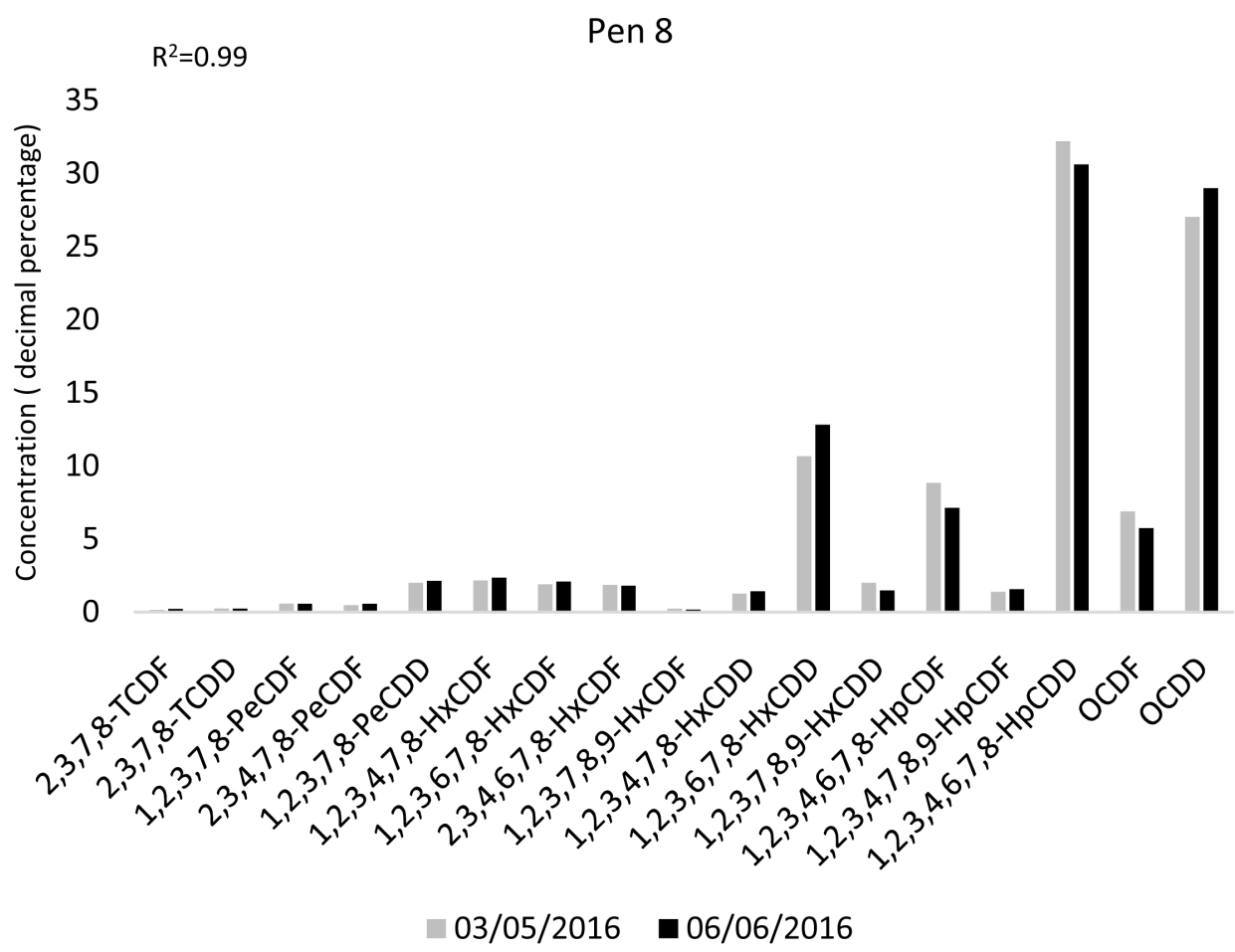

Figure 4. Assessment of contamination profile in Pen 8.

The comparison of the profile of the average contamination of the bedding material and all the samples collected from muscle and fat of the different pens with ducks is presented in Figure 8. 


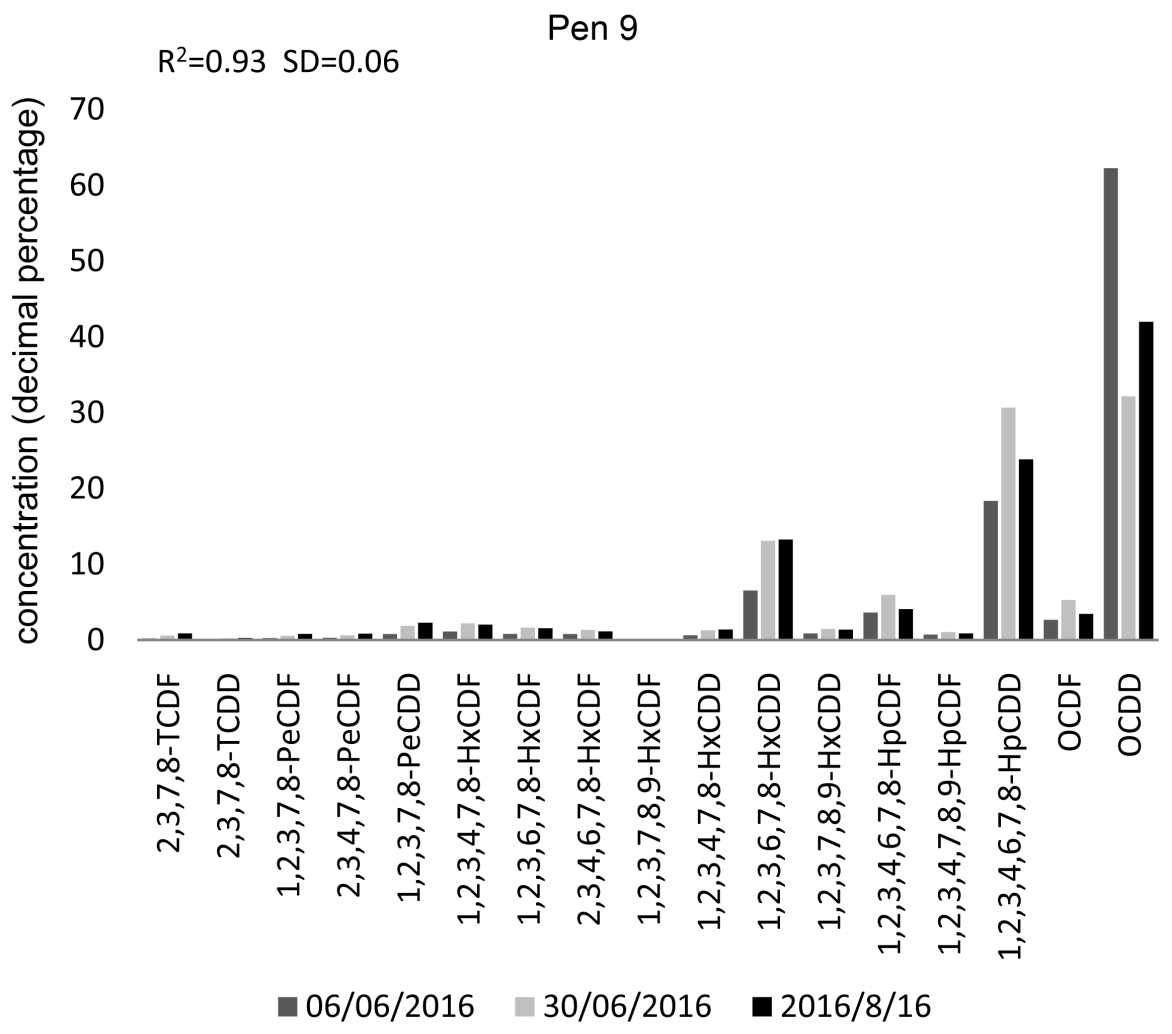

Figure 5. Assessment of contamination profile in Pen 9.

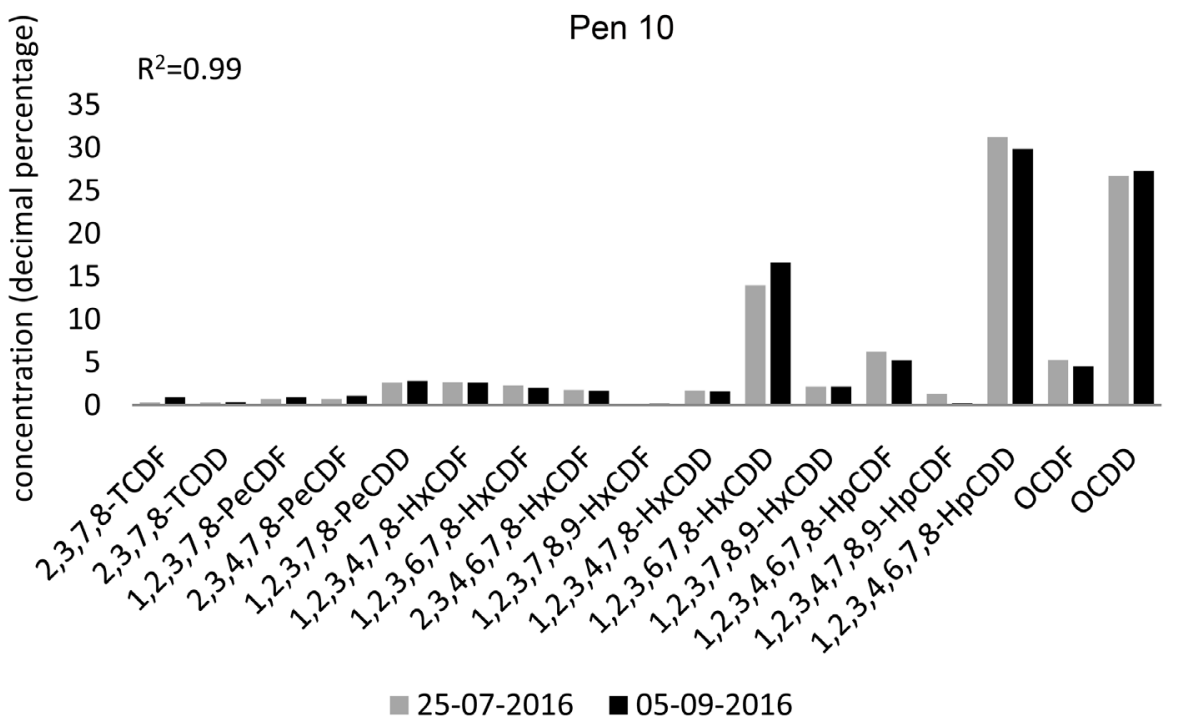

Figure 6. Assessment of contamination profile in Pen 10.

\section{Discussion}

The contamination levels found in the poultry meat exceeded the maximum limit allowed by the European legislation for these substances in poultry meat, set at $1.75 \mathrm{pg}$ PCDD/F-WHO-TEQ/g fat [9]. 


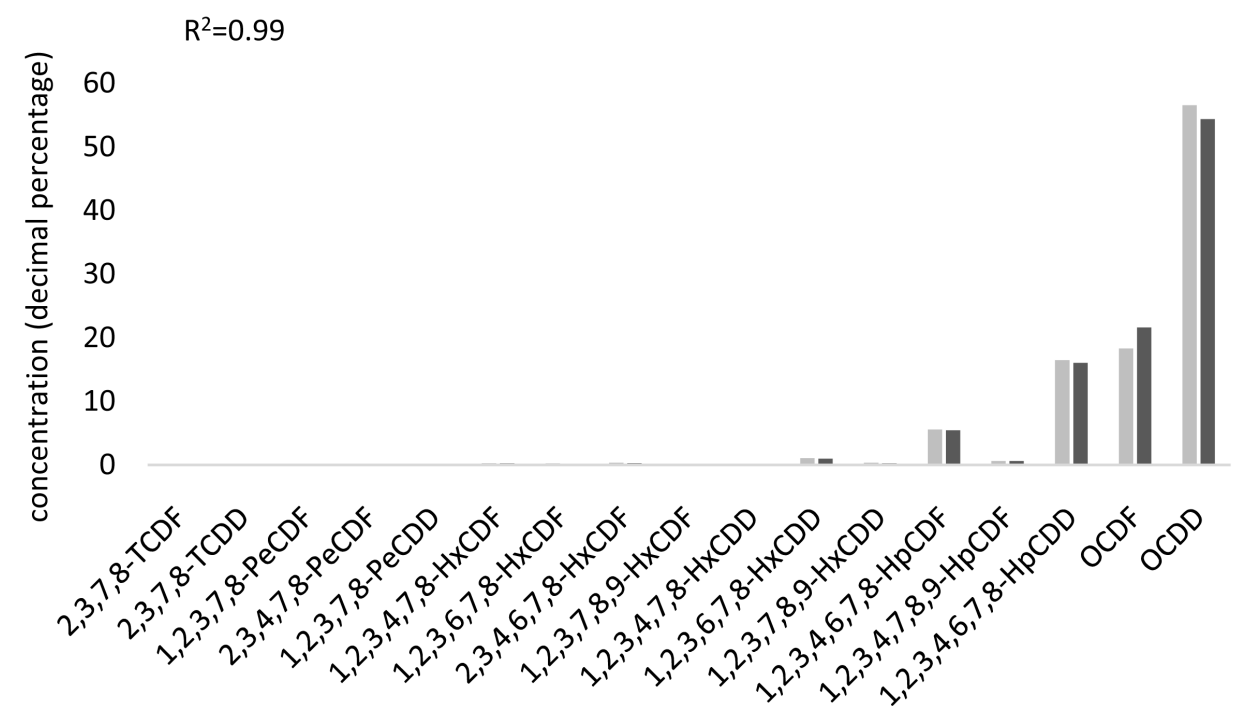

Figure 7. Wood shavings contamination profile.

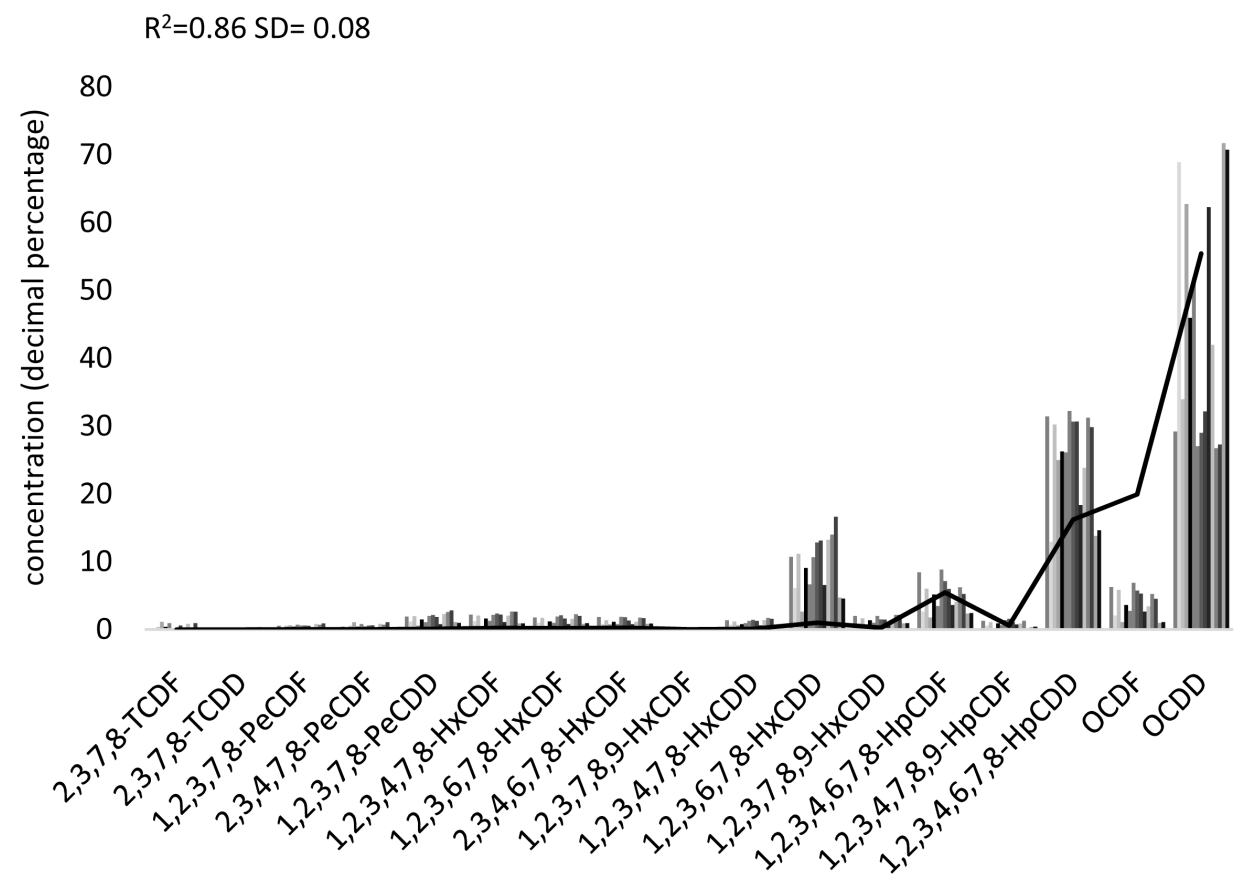

Figure 8. Comparison wood shavings from bedding material (line) and muscle and fat of ducks.

The study of the incident occurred during 2016 in the duck production holding revealed a reduction of contamination after the removal of the source of contamination, with an average daily depletion percentage level ranging between $1.43 \%$ and $4.35 \%$.

Hoogenboom, L. et al. found depletion rates of $4.7 \%$ in broilers in a tree weeks' elapse period, however the contamination profile was significantly different, being the least chlorinated congeners the predominant in the overall contamination [4]. The author states that the least chlorinated congeners decrease more rapidly than the higher 
chlorinated congeners.

Several factors may contribute to influence the depletion level. This number of variables in addition to the few results in each affected pen did not allow the confirmation of what was previously expected, i.e. that the depletion level is influenced by the level of initial contamination, by the age of the ducks, that is, with the growth rate (dilution effect), by weight of the ducks and by the elapsed time.

The variables, except for the initial contamination, showed very similar quantitative values:

- The first analysis in all pens were made in ducks in the same production stage, the last third of fattening, i.e., during the finishing phase, shortly before the expected date of slaughter, which is the period when they show lower growth rates;

- The second analysis in the positive pens were made, with one exception, not later than 110 days of live, despite the decision to extend the life of animals with the expectation that their contamination would be reduce after changing the bedding material. However, with the exception of four samples, the life time could not be further extended due to the fact that slaughter of ducks after 90 days is not advantageous from a commercial point of view. Furthermore, there was the need to ensure that there were no welfare problems by overpopulation of the pens, i.e. as the ducks grow older, the vital free space for each one gets tighter, with losses in animal health and mortality. These conditions did not allow to extend the depletion time in at least some pens.

The depletion rate (average daily depletion percentage) has a negative association with the depletion period (Figure 9). In the case of pen 1, in which the bedding material was replaced by rice husk later, one week after the first sample, the depletion rate showed negative values.

In some pens, there was an increase of the most chlorinated congeners (pen 1, 2 and

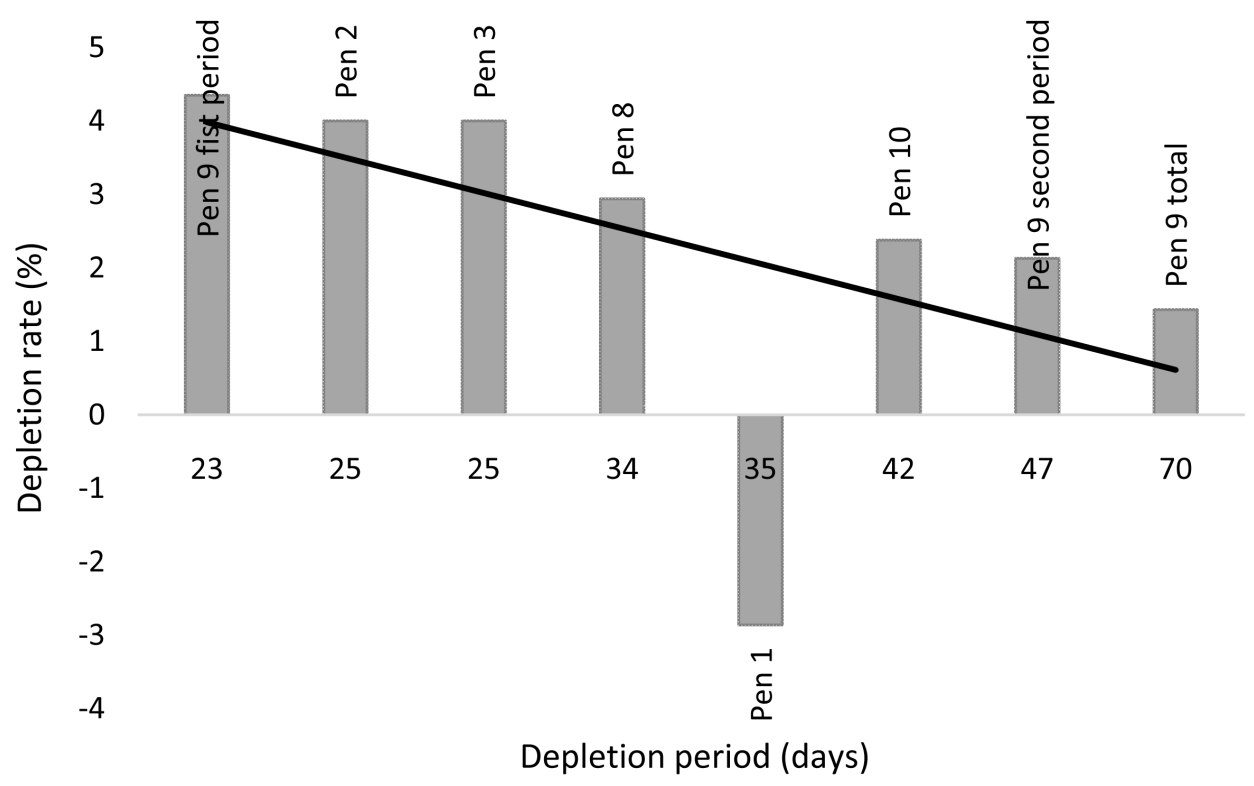

Figure 9. Depletion rate variation with the depletion period in days. 
3), in another pen, precisely the opposite happened (pen 9) and yet, there were two other pens in which the profile has remained unchanged (pen 8 and pen 10). This lack of consistency in the behavior of the congeners relative concentration does not allow to draw up conclusions concerning the profiles in the different pens.

The pattern detected in the wood shavings matches with the profile found in contaminated wood shavings obtained from treated wood by other authors [10] [11]; this suggests that the wood shavings used in the litters were obtained from treated wood, being the wood preservative the possible source.

The assessment carried out between the profiles found in the wood shavings samples and the muscle fat of the ducks reared on those litters showed a coincidence of peaks of higher relative concentration in each samples. These results concern in particular the relative concentrations of the congeners $1,2,3,4,6,7,8-\mathrm{HpCDD}$ and OCDD [12]. Graphic representation of the relative concentrations of the different dioxin congeners in each matrix had different comparative expressions. For example, in the duck muscle fat profiles, the average relative concentration of OCDD and OCDF was respectively $18 \%$ and $81 \%$ lower, comparatively to the wood shavings. On the other hand, the average relative concentration of $1,2,3,6,7,8-\mathrm{HxCDD}$ and $1,2,3,4,6,7,8-\mathrm{HpCDD}$ in the duck muscle fat profiles was respectively $89,4 \%$ and $35,4 \%$ higher when compared with the litters.

In the wood shavings, the concentration of the three most chlorinated congeners $(1,2,3,4,6,7,8-\mathrm{HpCDD}$, OCDF and OCDD) represents $91.6 \%$ of the total concentration of the 17 congeners, while, in the muscle and fat of the contaminated duck analysis it represents only $74.4 \%$.

The figures suggest that, probably, there are some factors which may affect the consistency in quantitative terms of the relative concentration of congeners found in wood shavings and in duck muscle fat. Several explanations could justify this lack of consistency: A dechlorination of the most chlorinated congeners due to an "in vivo" metabolic pathway; a differentiation on the lipophilic affinity of each congener; variations on the affinity to the Ah receptor and selective faecal excretion by the birds, also equivalent to a lower absorptive capacity [13] [14].

\section{Conclusions}

This study clearly identified the source of the duck farm contamination, taking into account the relationship established with an environmental vehicle of dioxins (wood shavings). This achievement is based on the consistency of the results obtained with all the tested materials regarded as potential contamination source and the fingerprint analysis of the relative concentration of the 17 dioxin congeners.

This study was developed in a real scenario, involving 20,000 animals and subjected to legal constraints. These are related to animal welfare (excessive weight, husbandry area and animal density) and the deadlines imposed on official services to take action against the results found, as well as economic interests of the producer involved in the incident, limiting the depletion times applied in each pen and the number of analyses performed. Despite these constraints, it was concluded that this study in a duck farm, 
revealed a reduction of contamination in muscle and fat of the ducks after the removing the source of contamination, with an average daily depletion percentage level (depletion rate) ranging between $1.43 \%$ and $4.35 \%$. These results do not allow to establish a fixed depletion rate for ducks, since it is not possible to establish a pattern associated with age or initial contamination level. Furthermore, it was concluded that pens with shorter estimated depletion period, showed higher average daily depletion percentage. This fact indicates that the average daily depletion percentage decreases over time after the removal of the contamination source.

\section{References}

[1] McLachlan, M.S. and Richter, W. (1998) Uptake and Transfer of PCDD/Fs by Cattle Fed Naturally Contaminated Feedstuffs and Feed Contaminated as a Result of Sewage Sludge Application. 1. Lactating Cows. Journal of Agricultural Food Chemistry, 46, 1166-1172. https://doi.org/10.1021/jf970922u

[2] Fries, G.F., Paustenbach, D.J., Mather, D.B. and Luksemburg, W.J. (1999) A Congener Specific Evaluation of Transfer of Chlorinated Dibenzo-p-Dioxins and Dibenzofurans to Milk of Cows Following Ingestion of Pentachlorophenol-Treated Wood. Environmental Science and Technology, 33, 1165-1170. https://doi.org/10.1021/es981153d

[3] Malisch, R. (2000) Increase of the PCDD/F-Contamination of Milk, Butter and Meat Samples by Use of Contaminated Citrus Pulp. Chemosphere, 40, 1041-1053. https://doi.org/10.1016/S0045-6535(99)00352-5

[4] Hoogenboom, L., Kan, C., Bovee, T., Van der Weg, G., Onstenk, C. and Traag, W. (2004) Residues of Dioxins and PCBs in Fat of Growing Pigs and Broilers Fed Contaminated Feed. Chemosphere, 57, 35-42. https://doi.org/10.1016/j.chemosphere.2004.04.057

[5] Pirard, C. and De Pauw, E. (2005) Uptake of Polychlorodibenzo-p-Dioxins, Polychlorodibenzofurans and Coplanar Polychlorobiphenyls in Chickens. Environment International, 31, 585-591. https://doi.org/10.1016/j.envint.2004.10.008

[6] United States Environment Protection Agency (1994) Method 1613 Revision B-TetraThrough Octa-Chlorinated Dioxins and Furans by Isotope Dilution HRGC/HRMS. United States Environment Protection Agency, Washington DC, 89.

[7] Russell, H. and Plumb, J. (2004) Fingerprint Analysis of Contaminant Data: A Forensic Tool for Evaluating Environmental Contamination. National Exposure Research Laboratory Environmental Sciences Division, Las Vegas, 27.

[8] Johnson, R. and Wichern, D. (2001) Applied Multivariate Statistical Analysis. 5th Edition, Prentice Hall, Upper Saddle River, 761.

[9] Commission of the European Communities (2006) Commission Regulation (EC) No 1881/ 2006 of 19 December 2006. Setting Maximum Levels for Certain Contaminants in Foodstuffs. OJL 364, 20 December 2006, p. 5.

[10] Hagenmaier, H. and Brunner, H. (1987) Isomer Specific Analysis of Pentachlorophenol and Sodium Pentachlorophenate for 2,3,7,8-Substituted PCDD and PCDF at Sub-PPB Levels. Chemosphere, 16, 1759-1764. https://doi.org/10.1016/0045-6535(87)90164-0

[11] Fries, G.F., Feil, V. and Davison, K. (1996) The Significance of Pentachlorophenol-Treated Wood as a Source of Dioxin Residues in United States Beef. Organohalogen Compounds, 28, 156-159.

[12] Cardo, M.O., Castel-Branco, M., Andreozzi, V. and Bernardo, F.A. (2014) Dioxins in the 
Food Chain: Contamination Fingerprint Analysis in Breeding Hens, Hatching Eggs and Broilers. Journal of Environmental Protection, 5, 1323-1330.

https://doi.org/10.4236/jep.2014.513126

[13] Lynam, M., Kuty, M., Damborsky, J., Koca, J. and Adriaens, P. (1998) Molecular Orbital Calculations to Describe Microbial Reductive Dechlorination of Polychlorinated Dioxins. Environmental Toxicology and Chemistry, 17, 988-997.

https://doi.org/10.1002/etc.5620170603

[14] Pirard, C. and Pauw, E. (2004) Uptake of Polychlorodibenzo-p-Dioxins, Polychloro-Dibenzofurans and Coplanar Polychloro-Biphenyls in Chickens. University of Liège, Liège, Belgium. Environment International, 31, 585-591.

https://doi.org/10.1016/j.envint.2004.10.008

Submit or recommend next manuscript to SCIRP and we will provide best service for you:

Accepting pre-submission inquiries through Email, Facebook, LinkedIn, Twitter, etc. A wide selection of journals (inclusive of 9 subjects, more than 200 journals)

Providing 24-hour high-quality service

User-friendly online submission system

Fair and swift peer-review system

Efficient typesetting and proofreading procedure

Display of the result of downloads and visits, as well as the number of cited articles

Maximum dissemination of your research work

Submit your manuscript at: http://papersubmission.scirp.org/

Or contact jep@scirp.org 